\title{
Presença do cordel no Romance d'A Pedra do Reino e o Príncipe do Sangue do Vai-e-Volta: o problema da autoria
}

\author{
José Nogueira da Silva" \\ Adriana Cavalcanti dos Santos**
}

\section{Resumo}

$\mathrm{O}$ artigo define por objetivo realizar uma elucubração acerca do diálogo entre os textos literários e a ideia de autoria, além de repensar esses conceitos através da busca da influência da literatura de cordel na obra $R o$ mance d'A Pedro do Reino e o Príncipe do Sangue do Vai-e-Volta, verificando o hibridismo que permeia a linguagem. Os resultados demonstram que, embora se perceba a presença de fragmentos de textos da literatura de cordel na obra analisada, para além das relações de plágio ou de intertextualidade, o de que autor e leitor são ambos os indivíduos realizadores de leituras, toda leitura é uma releitura e toda escrita, uma reescrita.

Palavras-chaves: Literatura de cordel. Romance. Autoria.

\section{Para iniciar a prosa...}

A noção de autoria é algo ainda muito complexo em determinados momentos históricos, pois as fronteiras entre aquilo que se entende como plágio e intertextualidade estão longe de serem rigidamente definidas, talvez nem necessite

\footnotetext{
* Mestre em Literatura. Doutorando em Educação pela Universidade Federal de Alagoas. Membro do Grupo de Estudo e Pesquisa em Didáticas de Leitura, da Literatura e da Escrita (GELLIT). E-mail: nogueiraviola@ hotmail.com

** Professora adjunta da Universidade Federal de Alagoas (UFAL-BRASIL), líder do Grupo de Estudo e Pesquisa em Didáticas de Leitura, da Literatura e da Escrita (GELLIT). Pós-Doutora pela Faculdade de Psicologia e de Ciências da Educação da Universidade do Porto (FPCEUP), sob supervisão da professora catedrática Dra. Carlinda Leite. Atua como professora dos quadros permanentes do Programa de Pós-Graduação em Educação (PPGE/CEDU/UFAL) e do Programa de Pós-Graduação em Ensino de Ciências e Matemática (PPGECIM). Os seus interesses de investigação são: Ensino de Língua Portuguesa; Formação de professores; Currículo e modos de trabalho pedagógico na educação básica. Tem coordenado projetos de iniciação científica UFAL/CNPq. É autora de artigos publicados em livros e em revistas nacionais. E-mail: adricavalcanty@hotmail.com
}

Data de submissão: set. 2020 - Data de aceite: nov. 2020 http://dx.doi.org/10.5335/rdes.v16i3.9483 
de tais delimitações, já que as definições fixas têm se demonstrado como tentativas frustradas no estudo da linguagem.

O presente artigo define por objetivo realizar uma elucubração acerca do diálogo entre os textos literários e a ideia de autoria, além de repensar esses conceitos através da busca da influência da literatura de cordel na obra Romance d'A Pedro do Reino e o Príncipe do Sangue do Vai-e-Volta, verificando o hibridismo que permeia a linguagem. Para isso, realizou-se uma investigação qualitativa, do tipo análise documental.

Como embasamento teórico, neste artigo, dialoga-se com três autores e obras; Michel Foucault, com o texto "O que é um autor?" (2009), Roland Barthes, com "A morte do autor" (1988), e Mikhail Bakhtin, com Estética da criação verbal (2003). As três abordagens possuem distintas considerações, no entanto são convergentes no que dizem respeito à ideia de que o autor como pessoa humana é distinto do conceito de autor como o indivíduo que organizou o texto, usando um sistema de signos no qual foi imerso, por isso não foi o criador e sim o articulador, pois o texto possui diálogos com outros textos, desconstruindo assim a ideia de plágio e do texto como propriedade do autor.

O suporte teórico supracitado é necessário para se analisar a presença de narrativas encontradas na literatura de cordel em meio à obra Romance d'A Pedro do Reino e o Príncipe do Sangue do
Vai-e-Volta, de Ariano Suassuna (2007), autor que defende o Movimento Armorial, no qual as culturas denominadas como eruditas e populares são amalgamadas. Esse processo permite que narrativas populares do cordel consigam ser parte significante de uma narrativa, mesmo que as estórias do cordel sejam em sextilhas, algo que derruba as barreiras ideológicas não somente entre 0 erudito e o popular, mas também entre a prosa e a poesia.

Mediante o exposto, o artigo é tecido em três partes que se complementam. $\mathrm{Na}$ primeira, discute-se o conceito de autoria sob diferentes perspectivas. $\mathrm{Na}$ segunda, evidencia-se a presença da literatura de cordel na obra Pedra do Reino. Na terceira, são apresentadas as considerações finais.

\section{Ecos de diversas vozes: o que é um autor?}

Para servir como aporte teórico, é lícito trazermos à baila "O que é um autor?", de Michel Foucault (2009). Nessa obra, perceberemos que a ideia de autor faz parte de um discurso que é distinto da ideia medieval de autor, já que nesta não predominava a busca pelo fechamento da obra, já que, no ato de cópia, havia também um processo de aperfeiçoamento de texto, no entanto, depois da Renascença, alguns fatores sociais, políticos e econômicos foram determinantes para 0 
engendramento e a elevação do indivíduo, o que equivale à ideia de autor no campo da arte. Um bom exemplo desses fatores é encontrado nos textos heréticos medievais e na busca por um culpado por tal criação, forçando o discurso vigente a reconhecer a ideia de autoria, ficando o texto na dualidade entre o sagrado e o profano (FOUCAULT, 2009, p. 274-275).

Levando em conta o raciocínio supracitado, compreende-se que a função do autor passa a ser a de possuir diferentes discursos nas sociedades onde circulam, sendo vistos por muito tempo como fechados, com leitores inconscientes ao ato da escritura inerente ao escrito; sendo o discurso do autor um mecanismo de apropriação de um discurso reconhecido como literário, estabelecendo também a ideia de origem nesse.

A respeito da ideia de autoria, Roland Barthes (1988), em "A morte do autor", entende esse conceito como uma criação moderna, afirmando que em um texto não é o autor que enuncia, mas uma linguagem, defendendo que a escrita prevalece em detrimento da voz. Tal diminuição de poder do autor é compreensível pelo gradativo aumento da ênfase no leitor, no seu espaço, na sua importância, pois o texto é construído por inúmeras escrituras provenientes de várias culturas dialogando entre si sob diversas maneiras, encontrando no leitor a oportunidade para se revelar. Infelizmente toda ênfase que foi dada, por séculos, aos autores e às suas supostas influências no texto foi negada radicalmente ao leitor. Nas palavras do autor:

Esse lugar não é o autor, como se disse até o presente, é o leitor: o leitor é o espaço mesmo onde se inscrevem, sem que nenhuma se perca, todas as citações de que é feita a escritura; a unidade do texto não está em sua origem, mas no seu destino, mas esse destino não pode mais ser pessoal: o leitor é um homem sem história, sem biografia, sem psicologia, ele é apenas alguém que mantêm reunidos em um único campo todos os traços de que é constituído o escrito. (BARTHES, 1988, p. 70).

Portanto, para Barthes, o escritor e o leitor são indivíduos sem aspectos psicológicos, históricos e biográficos, já que seus caracteres estão resumidos ao ato de leitura e produção textual, sendo ambos produtores de texto.

Para a tessitura desse diálogo, Mikhail Bakhtin (2003) traz outra grande contribuição para a noção de autoria como um discurso que se apropria de uma escrita que antecedeu o indivíduo que compôs, sendo essa, propriedade de um corpo coletivo, um tecido social que envolve o autor desde o seu nascimento e o constitui, continuando a viver em constante movimento após sua morte biológica ou até mesmo teórica. Nesse caso, temos a consideração do âmbito psicológico, histórico e até mesmo biológico dos seres envolvidos no ato de escritura e leitura do texto.

Em $O$ autor e a personagem na atividade estética, de Mikhail Bakhtin (2003), o autor faz uma divisão classificatória 
entre autor-criador, ou seja, a obra, e autor-pessoa, o indivíduo dotado de vida biológica, pois tal confusão resulta no mau entendimento do processo de criação na relação entre autor e a personagem. Tal diferenciação é coerente com a de Barthes (1988), dadas suas devidas distinções, ao diferenciar autor e escritor, pois este não considera o autor um indivíduo biográfico, histórico, biológico e psicologicamente constituído, mas um sujeito com uma existência pautada no universo textual. "O autor nunca é nada mais para além daquele que escreve, tal como 'eu' outra coisa senão aquele que diz 'eu”' (BARTHES, 1988, p. 67). O cruzamento de ambos os autores deixa claro o que diferencia o autor como indivíduo biológico e como produtor de texto, não como alguém dotado das interpretações deste, mas como um enunciador de palavras pertencentes a um corpo social e com potencial plurissignificativo.

Assim, recorre-se novamente a Bakhtin (2003) para afirmar a ação do autor-pessoa que é identificada pela exotopia, "o fato de uma consciência ver a outra como um todo acabado, o que ela não pode fazer consigo mesma" (TEZZA, 2003, p. 282). Para Bakhtin (2003, p. 11):

$\mathrm{O}$ autor vivencia a vida da personagem em categorias axiológicas inteiramente diversas daquelas em que vivencia sua própria vida e a vida de outras pessoas - que com ele participam do acontecimento ético aberto e singular de sua existência -, apreende-a em um contexto axiológico inteiramente distinto.
Apesar de os textos não terem dialogado de maneira direta, pois cada autor tem seu repertório particular de referências e reflexões, cada um deles percebeu que a herança teológica de buscar saber o pensamento do autor não ficou no século XIX, ainda há brasas dessa fogueira. Isso explica o esforço em enfatizar a morte do autor, a independência do texto, a liberdade interpretativa, a importância do leitor, o diálogo incessante do texto com passadas e futuras gerações, $o$ texto supera os limites temporais e espaciais do autor no que concerne ao seu potencial dialógico.

Seguindo a reflexão dos mesmos objetos, enquanto Barthes falou da morte do autor, Foucault (2009) trata de diversas reflexões sobre compreender quem ou o que é o autor, entre elas fala também da aproximação entre a escrita e a morte, considerado por ele como algo que "subverte um tema milenar; a narrativa, ou a epopeia dos gregos, era destinada a perpetuar a imortalidade do herói, e se o herói aceitava morrer jovem, era porque sua vida, assim consagrada e magnificada pela morte, passa à imortalidade" (FOUCAULT, 2009, p. 268). Em seu entendimento, a narrativa mantém a juventude dos heróis a um ponto de sua imortalidade na narrativa ser mais importante que sua passagem enquanto vivo biologicamente.

O mesmo ele encontra nas narrativas árabes ao falar de As mil e uma noites 
como uma obra na qual a motivação da personagem era não morrer, o estímulo para o deslindar da estória, algo desenrolado até o amanhecer e assim, afastando a morte, um esforço repetido todas as noites para vencer e manter a morte afastada, pois ela está à espreita o tempo todo, aguardando um deslize da heroína que narra.

Depois, Michel Foucault nos relata a ligação não exatamente com a morte, mas com o sacrifício, o da vida no caso, um apagar voluntário não representado na escrita, não obstante materializado na subsistência do escritor.

A obra que tinha o dever de trazer a imortalidade recebeu agora o direito de matar, de ser assassina do seu autor. Vejam Flaubert, Proust, Kafka. Mas há outra coisa: essa relação da escrita com a morte também se manifesta no desaparecimento das características individuais do sujeito que escreve; através de todas as chicanas que ele estabelece entre ele e o que ele escreve, o sujeito que escreve despista todos os signos de sua individualidade particular; a marca do escritor não é mais do que a singularidade de sua ausência; é preciso que ele faça o papel do morto no jogo da escrita. Tudo isso é conhecido; faz bastante tempo que a crítica e a filosofia constataram esse desaparecimento ou morte do autor. (FOUCAULT, 2009, p. 269).

Se houve, na última frase supracitada, uma alusão a Barthes, fica a dúvida, pois seria irônico buscarmos a intenção do autor em um texto que trata da morte deste. Mas a escrita nos deixa tal impressão, assim como Barthes (1988, p. 70), quando diz que "o nascimento do leitor deve pagar-se com a morte do autor". Apesar de Bakhtin não ter vivido no mesmo contexto físico de Barthes e Foucault, ele também enfatiza a incoerência de confundir o pensamento do autor e do personagem, salienta a dialogicidade entre o indivíduo e o corpo coletivo da linguagem, este como um organismo vivo e aquele com um possuidor e transformador deste, apesar de não ter controle sobre a pluralidade significativa que a língua contém. Para analisar tais fenômenos, ele propõe uma filosofia estética que substitua generalizações pseudocientíficas da história da literatura, porque uma análise pautada em critérios convenientes, mas pouco eficazes, como a crítica biográfica ou a valorização velada da biografia, apenas diminui as possibilidades de compreendermos a estrutura do texto e o potencial dentro do qual se apresenta ao leitor.

\section{Presença do cordel na Pedra do Reino}

A literatura de cordel tem uma presença marcante na obra Romance d'A Pedra do Reino e o Príncipe do Sangue do Vai-e-Volta, por essa razão, ao analisar os aspectos literários de cordel da referida obra, percorre-se as fronteiras entre o cordel e seu hibridismo com outras expressões que compõem o Movimento Armorial (SUASSUNA, 2007). 
Em primeiro lugar, é interessante levar em conta a importância, dada pelo autor, das características marcantes do cordel, uma delas é a oralidade, algo identificado tanto nos contatos de Quaderna com o cantador Lino Pedra Verde quanto nas influências recebidas por sua Tia Filipa, que repassara diversas cantigas, canções estas que tiveram grande valia na formação intelectual de Quaderna. Pode-se encontrar esses traços marcantes no Folheto XI do I livro, chamado: "A aventura de La condessa", em que se percebe que as cantigas populares eram repassadas para crianças de forma lúdica. Segundo Maioli (2008, p. 81):

É interessante frisar que o mesmo trecho
também coloca em evidência o papel da ora-
lidade como veículo responsável pela difusão
do legado da cultura popular. Isto é consta-
tado no instante em que o narrador lembra
de Filipa tecendo suas rendas, ao mesmo
tempo em que cantava velhas cantigas e
folhetos que havia decorado. Mais adiante,
a transmissão oral destes substratos é rea-
firmada na menção feita aos jogos infantis
por ela comandados.

Nesse mesmo capítulo, o autor deixa claro que as influências populares de Quaderna provêm das experiências poéticas predominantemente orais, a exemplo das aulas com o cantador Lino Pedra Verde e as estórias que sua tia contava, narrativas que germinaram na imaginação de Quaderna ao afirmar que a presença popular no seu estilo realçaria ainda mais a sua "Obra máxima”. Pode-se encontrar em Quaderna a experiência de inúmeros sertanejos, que repassaram, de geração a geração, as histórias contadas tanto nos alpendres das fazendas como nos mais simplórios terreiros de agricultores sertanejos, que descobriram nas narrativas orais e leituras de cordéis não apenas uma leitura, mas um momento de alegria e fuga das dificuldades vividas. Bakhtin (2003, p. 188) nos fala da formação cultural do indivíduo como uma linha tênue entre a sua subjetividade e as idiossincrasias com as quais dialoga:

A vida procura recolher-se ao esquecimento adentrando a si mesma, migrar para sua infinitude interior, teme as fronteiras, procura desintegrá-las, uma vez que não acredita na essencialidade e na bondade da força que forma de fora; rejeição do ponto de vista de fora. Neste caso, evidentemente, a cultura de fronteiras - condição indispensável de um seguro e profundo - se torna impossível, é precisamente com as fronteiras da vida que nada se tem a fazer; todas as energias criadoras migram das fronteiras e por isso pressupõe um clima caloroso de profunda confiança que abarque a vida.

Além dessas características, encontra-se também uma série de citações de cordelistas diversos, tais citações reafirmam a preocupação do autor em evidenciar a suposta autoria dos versos, já que muitos dos cordelistas são destacados e não apenas os versos feitos por eles. Alguns cordelistas de grande respaldo no meio popular, como João Melchíades Ferreira, João Martins de Athayde e Leandro Gomes de Barros, são citados na obra 
de Ariano Suassuna (2007). No entanto, também se encontra uma série de cordéis citados sem ser dada a sua autoria, como o folheto A louca no jardim ou $\mathrm{O}$ assassino da honra, sendo o folheto de autoria de Caetano Cosme da Silva, poeta que tem o cordel citado na obra de Ariano, mas não a autoria, o que não nos leva a apontar algum mérito ou demérito de Ariano Suassuna, apenas constatamos o fato, muito embora o reconhecimento de certos nomes na poesia popular apenas enriqueça a nossa literatura, já que suas obras causam influências não apenas na Pedra do Reino (SUASSUNA, 2007), mas em toda a bibliografia de Ariano Suassuna. Corroborando a discussão, Cardoso (2010, p. 132-133) afirma que:

Para os artistas armoriais, o "folheto de cordel" será a mais completa dentre as manifestações, pois nele está incluída a xilogravura, no desenho da capa, os versos e ainda a voz, que, a despeito do suporte impresso do verso não é omitida, dado o fato de que o público do cordel se reúne ainda para escutar em leituras coletivas a voz do contador, sem mencionar que os recursos mnemônicos próprios do cordel facilitam a apreensão da história e sua propagação oral... ele é, dessa maneira, a manifestação popular que sem dúvida maior influência exerce sobre os artistas do Movimento Armorial e, em especial, sobre Ariano Suassuna e sua literatura.

Portanto, falar da literatura de cordel na obra de Ariano Suassuna é falar de uma das maiores ou talvez a maior influência literária do Movimento Armorial e, consequentemente, das suas obras. No caso da Pedra do Reino (SUAS-
SUNA, 2007), a primeira influência é encontrada na própria divisão feita dos capítulos, em que ele divide cada capítulo em livros e cada livro é subdividido em folhetos, reafirmando a ideia da intensa aproximação entre o "romance" de Ariano e a literatura popular nordestina. Em relação aos títulos desses folhetos, nota-se que alguns são uma apropriação de cordéis já publicados no meio popular, como o folheto XLVI, denominado de $O$ Reino da Pedra Fina, título de um folheto de cordel lançado pelo poeta Leandro Gomes de Barros, algo especificamente encontrado também no folheto LXVI, chamado A filha noiva do pai, ou amor, culpa e perdão, título de um dos cordéis do escritor popular Joaquim Batista Sena.

Nos dois casos se encontra não somente a apropriação dos títulos, mas também a utilização de uma técnica muito usada na literatura de cordel, principalmente na primeira metade do século XX, que é a utilização de dois títulos em um mesmo episódio, "cujo fim é suscitar a curiosidade do leitor, visto que lhe oferece duas facetas instigantes acerca dos assuntos abordados pelo enredo de determinado livreto" (MAIOLI, 2008, p. 71). Além do mais, os títulos "reutilizados" são de obras consideradas verdadeiros clássicos da literatura popular, portanto a escolha dos cordéis que "inspiram" Ariano não é feita despreocupadamente, mas de forma minuciosa, para sua obra conter aquilo 
que a poesia popular tem de melhor, no entendimento do autor. Para Foucault (2009), a noção de escrita é um entrave para a certeza o sumiço do autor e se mantém numa linha tênue com essa anulação.

Uma outra noção, acredito, bloqueia a certeza da desaparição do autor e retém como que o pensamento no limite dessa anulação; com sutileza, ela dina preserva a existência do autor. É a noção de escrita. A rigor, ela deveria permitir não somente dispensar a referência ao autor, mas dar estatuto à sua nova ausência. No estatuto que se dá atualmente à noção de escrita, não se trata, de fato, nem do gesto de escrever nem da marca (sintoma ou signo) do que alguém teria querido dizer; esforça-se com uma notável profundidade para pensar a condição geral de qualquer texto, a condição ao mesmo tempo do espaço em que ele se dispersa e do tempo em que ele se desenvolve. (FOUCAULT, 2009, p. 270).

Na mesma obra, nota-se a presença de uma espécie de convite ao leitor, em que são relatadas diversas características que encontraremos no decorrer da obra, para em seguida duas sextilhas, sendo realizada uma espécie de invocação, algo típico das epopeias.

Como o enfoque, neste artigo, é na literatura de cordel, é de maior relevância ressaltar o texto anterior às sextilhas, no qual o escritor faz um resumo em forma de convite, técnica peculiar dos folhetos de cordel, que foi assimilada pelo autor, e mesmo sendo reproduzida em forma de romance, e sua função continua inabalável. Para Suassuna (2007, p. 27):
Romance enigmático de crime e sangue, no qual aparece o misterioso Rapaz-do-cavalo-branco. A emboscada do lajedo sertanejo. Notícia da pedra do reino, com seu castelo enigmático, cheio de sentidos ocultos! Primeiras indicações sobre os três irmãos sertanejos, Arésio, Silvestre e Sinésio! Como seu pai foi morto por cruéis e desconhecidos assassinos, que degolaram o velho rei e raptaram o mais moço dos jovens príncipes, sepultando-o numa masmorra onde ele penou durante dois anos! Caçadas e expedições heróicas nas serras do sertão! Aparições assombratícias e proféticas! Intrigas, presepadas, combates e aventuras nas caatingas! Enigma, ódio, calúnia, amor, batalhas, sensualidade e morte!

Diante desse pressuposto, percebemos que a sensibilidade do autor foi capaz de absorver diversas técnicas da literatura popular, ou seja, ele não enxergou apenas o óbvio, como a rima e a métrica, mas as outras peculiaridades existentes nos folhetos populares. Dessa maneira, o texto é, ao mesmo tempo, um convite e um resgate da cultura popular, além de uma breve sinopse da obra. Nesse ato, temos, nas palavras de Barthes (1988, p. 68-69), uma tessitura de citações estabelecidas em um texto:

Sabemos agora que um texto não é feito de uma linha de palavras a produzir um sentido único, de certa maneira teológico (que seria a "mensagem" do Autor-Deus), mas um espaço de dimensões múltiplas, onde se casam e se contestam escrituras variadas, das quais nenhuma é original: o texto é um tecido de citações, saídas dos mil focos da cultura.

Como já foi mencionado, nessa obra, muitos versos e nomes de cordéis e 
cordelistas são citados, além de aparecerem versos nos quais não são expostos nomes de obras ou autores "reais", responsáveis pelas estrofes, fazendo com que levantemos a hipótese de que os versos tenham sido produzidos pelo autor. Encontram-se essas evidências no Folheto III do I livro, em "A aventura da emboscada sertaneja”, quando Quaderna afirma que um homem chamado "Negro Ludugero" estava no intuito de atirar no "Rapaz-do-cavalo-branco", a personagem "Negro Ludugero" citou alguns versos em meio ao tiroteio:

Filha de branco,

Linda e clara como a lua!

Eu vou pegar você nua,

Mas não é para casar!

É pra lascar,

Que eu me chamo é Ludugero!

Eu nasci negro e só quero

Moça branca pra estragar!

(SUASSUNA, 2007, p. 52).

No verso supracitado, é fácil percebermos que sua estrutura difere dos cordéis, podendo ser classificada como uma cantiga popular, mas na literatura de cordel não encontramos nenhuma estrutura semelhante ao verso citado, muito menos nos cordéis do século XIX e início do século XX, sendo em quase sua totalidade escrito em sextilhas ou até mesmo quadras, mas sempre com uma estrutura pré-determinada e assimilada por um número significante de poetas. No entanto, tal rigorosidade popular não compromete o valor da obra de Ariano, que soube reproduzir magnificamente $o$ neologismo das nossas cantigas populares. Atualmente, a maioria dos cordéis ainda são escritos em sextilhas, porém, já se percebe em alguns cordéis a presença de décimas heptassilábicas ou decassilábicas, estas chamadas até hoje de martelo por muitos poetas. Cascudo (2000, p. 9) afirma que:

Decassílabos são os "martelos". Por que o sertanejo chama "martelo" a um verso de dez sílabas, com seis, sete, oito, nove ou dez linhas? Pedro Jaime Martelo (1665-1727), professor de literatura da Universidade de Bolonha, diplomata e político, inventou os "versos martelianos", ou simplesmente "martelos". Eram de doze sílabas, com rimas emparelhadas. Esse tipo de "alexandrino" nunca foi conhecido na poesia tradicional do Brasil. Ficou a denominação cuja origem erudita é visível em sua ligação clássica com os poetas portugueses do século XVII.

Na obra de Suassuna (2007), logo após se encontrar o verso em questão, o leitor depara-se com outra estrofe, dessa vez sem uma autoria clara, pois ele aparece na estrofe dando a impressão de ser um monólogo que relata, através da poética popular, a luta ocorrida em Taperoá. Porém, essa estrofe é distinta da anterior, pois sua estrutura formal é coerente com a estrutura estrófica popular: 
E era um barulho danado, Todo esse povo atirando!

As balas, por perto dele,

Passavam no Ar, silvando!

O tiroteio imitava

Um Tabocal se queimando!

(SUASSUNA, 2007, p. 52).

Independente de quem seja a autoria, sejam os versos fiéis ao estilo da literatura ou não, retratam fielmente muitas temáticas da literatura de cordel da época, entre elas há que se destacar a inclusão de reis, princesas e lutas ferrenhas entre bravos guerreiros, algo que Ariano fez esplendidamente. O palimpsesto na obra de Ariano enriquece o universo imagético do leitor, apesar de a intertextualidade se operar de maneira pouco sutil, isso a ponto de os fragmentos de outras obras serem facilmente identificados, mesmo assim, as leituras teóricas deixam claro que até a noção de plágio é algo recente e tem suas motivações históricas. O cenário poético da literatura de cordel é transposto e hibridizado em sua obra, formando um todo coeso e rico de imagens narradas na perspectiva de Quaderna, não na de Ariano (SUASSUNA, 2007).

\section{Considerações finais}

O presente artigo trouxe a proposta de realizar uma elucubração acerca do diálogo entre os textos literários e a ideia de autoria, além de repensar esses conceitos através da busca da influência da literatura de cordel na obra Romance d'A Pedro do Reino e o Príncipe do Sangue do Vai-e-Volta, verificando o hibridismo que permeia a linguagem.

A obra de Ariano Suassuna faz parte do que ele chama de Movimento Armorial, no qual há uma intensa presença de elementos da cultura tradicionalmente popular no Nordeste, inclusive o cordel, um dos principais, ou o principal elemento em suas obras.

A intertextualidade entre Pedra do Reino e a literatura de cordel vai além dos elementos narrativos. Temos a organização dos subcapítulos, chamados de folhetos, alguns com títulos de cordéis já publicados no meio popular, ou títulos duplos, algo também usual entre alguns cordelistas, as gravuras são nitidamente aproximadas das xilogravuras, que, embora não sendo um elemento essencial do cordel, estão presentes em grande parte de sua produção, felizmente Ariano chega a citar diversos cordelistas e cordéis.

Enfim, o trabalho enriqueceu ainda mais a sua obra com elementos de nossa literatura popular tradicional, demonstrando que o que ele chama de Movimento Armorial está presente em todos os textos, embora os armoriais sejam bem enfáticos no que dizem respeito à cultura popular, mas o que se entende como plágio não é denominado na literatura, levando em conta que autor e leitor 
são ambos os indivíduos realizadores de leituras; toda leitura é uma releitura e toda escrita, uma reescrita.

\section{Presence of cordel in Romance d'A Pedra do Reino e o Príncipe do Sangue do Vai-e- Volta: the problem of authority}

\section{Abstract}

The objective of this article is to elucidate the dialogue between literary texts and the idea of authorship, as well as to rethink these concepts through the search for the influence of Cordel's Literature in the work Romance of Peter of the Kingdom and the Prince of Blood of the Vai-e-Volta, verifying the hybridity that permeates the language. The results show that although we perceive the presence of fragments of texts of the Cordel Literature in the analyzed work, beyond the relations of plagiarism or intertextuality, that of which author and reader are both individuals who carry out readings, all reading is a rereading and all writing a rewrite.

Keywords: Cordel literature. Romance. Authorship.

\section{Referências}

BAKHTIN, Mikhail. Estética da criação verbal. Trad. Paulo Bezerra. São Paulo: Martins Fontes, 2003.

BARTHES, Roland. O rumor da língua. São Paulo, SP: Brasiliense S. A., 1988.

CARDOSO, Maria Inês Pinheiro. Cavalaria e picaresca no Romance d'A Pedra do Reino de Ariano Suassuna. São Paulo: Universidade de São Paulo, 2010.

CASCUDO, Câmara. Vaqueiros e cantadores: folclore poético do sertão de Pernambuco, Paraíba, Rio Grande do Norte e Ceará. Rio de Janeiro: Ediouro, 2000.

FOUCAULT, Michel. Estética: literatura e pintura, música e cinema. 2. ed. Rio de Janeiro: Forense Universitária, 2009.

MAIOLI, Juliana Beliacqua. Aspectos da literatura de cordel em A Pedra do Reino, de Ariano Suassuna. Assis: Universidade Estadual Paulista, 2008.

SUASSUNA, Ariano. Romance d'A Pedra do Reino e o Príncipe do Sangue do Vai-e-Volta. 9. ed. Rio de Janeiro: José Olympio Editora, 2007.

TEZZA, Cristovão. Entre a prosa e a poesia: Bakhtin e o formalismo russo. Rio de Janeiro: Rocco, 2003. 